\title{
The Process and Characteristics of Psychological Kidnapping: An Indigenous Model of Corruption in China
}

\author{
Yan Xu, Liying Jiao, Ruijie Xu, Qiudi Feng, Fang Wang, Jiang Jiang, and Changsheng Chen \\ Beijing Key Laboratory of Applied Experimental Psychology, National Demonstration Center for Experimental Psychology \\ Education (Beijing Normal University), Faculty of Psychology, Beijing Normal University, Beijing, China
}

\begin{abstract}
n this study, we investigated a psychological mechanism underlying the corruption of government officials, based on cultural factors in China. The proposed psychological kidnapping model describes how some bribers set up relations (guanxi, 关系) with bribees to conceal the intention of bribery and gradually lead them into corruption. Through text analysis, classification, and encoding of corruption cases, we defined the term psychological kidnapping, as well as its fundamental characteristics and the corresponding interaction process model (study 1). Using qualitative analysis, we confirmed the three stages of the process of corruption (attraction and acceptance, trust and integration, and collusion or fracture). In a further step, we unveiled three characteristics of psychological kidnapping, known as concealed resource delivery, imbalanced perceptions of corruption risk and cost for government officials, and soft menace from bribers. Then we explored the essential role of renging (人情) in study 2 as a key enabler of psychological kidnapping. We hope that this work can provide a theoretical base for the prevention of corruption in the public service sector in China.
\end{abstract}

Keywords: corruption, relationship formation, psychological kidnapping, renqing

How does a good official become corrupt in China? Good officials, as we all know, are honest and righteous. However, after a period of time in office, some begin to take bribes and steal public resources. How does this happen? Exploring and understanding the mechanisms behind this interaction process is crucial, especially for China, the world's second largest and still fast-growing economy.

Transparency International found that among the 168 countries evaluated for its 2015 Corruption Perception Index (CPI), two-thirds scored less than 50 out of a perfect score of $100 \%$ transparency. Corruption is a particularly troubling phenomenon in developing countries because of its large negative impact (Cameron, Chaudhuri, Erkal, \& Gangadharan, 2009). It has also been a prominent political and social problem in China during its recent social transformation period (Deng, Zhang, \& Leverentz, 2010; He, 2000; Ting, 1997; Wedeman, 2004, 2012), as evidenced by the high-pressure anti-corruption campaign launched by the Chinese government and Communist Party leaders (Dai, 2013; Guo \& Li, 2015; Sun \& Yang, 2016; Wu,
2016). The anti-corruption movement has become more and more vigorous in recent years (Han, 2016).

Early researchers' work on the cause of corruption focused mainly on macro elements, such as political, ideological, and social factors. Montesquieu (1794) believed that certain regimes were more inclined to be corrupted than the others, particularly authoritarian regimes. Mill's (1966) application of liberal theory considered corruption to be a result of governments' interference in a free market economy. A more modern macro theory of corruption is modernisation theory, which asserts that a society's corruption level is determined by its level of modernisation (Huntington \& Fukuyama, 1968).

More recently at the individual level, researchers, mainly economists, have focused on officials' behaviour as one influential factor in corruption. They have defined common corrupt activities as rent-seeking, a behaviour through which the officials use public power to grab benefits, or enterprises bribe officials to win public resources (Buchanan, Tullock, \& Tollison, 1983). The 
rent-seeking theory was developed under the framework of the principal-agent model, in which some situations require citizens (the principal) to authorise the power of allocating public resources to an agent, such as a civil servant (Mishra, 2004). The principal-agent relationship may cause asymmetry in information sharing, so the principal is unable to form an exact contract to regulate the agents' performance due to the lack of relevant information. Thus, when the economic benefit is large and monitoring is limited, the agent may decide to act corruptly, and rent-seeking occurs. Low relative earnings, high unemployment, and advertising will also influence the acceptance of bribes (Goel \& Rich, 1989).

However, a simple agency framework is unable to provide a solid and convincing explanation for more complex scenarios (Lambsdorff, 2002a). There is a common issue with interpretations based on economic theories, which all assume that corrupted officials are instrumental and benefit-seeking rent-seekers from the beginning and that corruption can be completed within a short period due to economic incentives and lack of monitoring. However, according to our study of corruption cases in China, these assumptions are not always consistent with actual corruption scenarios. First, for some corrupted officials, the benefits gained from bribery were so small that their value was far less than the risk of being caught. Furthermore, we found in some cases that bribery occurred after an unfair allocation of public resources, to close friends as a favour or from gratitude. Second, not all corrupt officials committed corruption at the beginning of their lieutenancy. Some officials with self-discipline stay away from corruption at first; some even proactively report and unveil the attempted bribes. In a word, political corruption cannot be considered as simply motivated by rent-seeking. Some officials might be enticed or seduced into corruption through an interpersonal process under certain social norms in which psychological factors play a very important role.

\section{Cultural Factors in the Psychology of Corruption}

Previous studies of corruption have found many factors associated with the extent of corruption. However, most of these cannot be applied directly to political interventions (Hunt, 2005). During recent years, researchers have begun to show interest in the role of Chinese culture in corruption, especially mianzi (face, 面子) and guanxi (relationships, 关系; Bedford, 2011; Han, 2016; Schramm \& Taube, 2003; Yu, 2008). In Chinese society, the interpersonal relationship can be categorised into two components: expressive components and instrumental components (Hwang, 1987, 2012a). As a result, there are three sorts of interpersonal relationships: the expressive tie (among members of such primary groups as family), the instrumental tie (opposite to the expressive tie, beyond family members in daily transactional life) and the mixed tie, with both elements, where an individual at- tempts to influence another person by means of renqing (norm of reciprocity) and mianzi (face). Development of the mixed tie goes through three successive stages: initiating, building, and using guanxi. Each stage has different goals, interactive behaviours, and rules of interaction (Chen \& Chen, 2004). An individual has to learn moral principles in accordance with the socio-moral order via socialisation to satisfy his/her own desire (Hwang, 2015b). In this case, the petitioner denotes the one who seeks social resources and asks other individuals in their social network for help. Then, the resource allocator will choose an appropriate rule for exchange. The Confucian ethical system of benevolence-righteousness-propriety ( ren-yi$l i$, 仁-义-礼) is used to make this choice according to the Confucian model of mind. The system contains a proper assessment of the intimacy or distance of the relationship (ren), an appropriate rule for the exchange according to the closeness of the relationship ( $y i)$ and proper action after evaluating the loss and gain of exchange (li). Different distributive rules for exchange are applicable to different types of relationships (guanxi) during social interactions (Hwang, 2001, 2012b, 2015a). In cases of corruption, if the guanxi between the allocator (the government official) and petitioner (the potential briber) is a mixed tie, the rule of exchange becomes ambiguous and the allocator is likely to be caught in dilemma of renqing: whether the allocator accepts the petitioner's request to unfairly allocate the public resources, or whether the guanxi between the two will be damaged, with the allocator being blamed for breaking the norm of reciprocity (renqing) of Confucian society.

Based on the literature and present situations, we decided to study the process of how good officials become corrupt from the perspective of officials themselves in Chinese culture. Specifically, we aimed to answer this question: How exactly does corruption start between an official and a briber in Chinese cultural context? Many people in Chinese society use mixed ties to place themselves in a more favourable position within other people's network in order to gain access to other people's resources (Hwang, 1987). We can infer that if a would-be petitioner wishes to persuade a stranger (the official) to allocate in their favour, specific means should be designed to involve the potential allocator into the petitioner's own social circle. When the petitioner interacts with the official in the mixed tie, the corruption can happen. Hence, we sought to establish an interactive model of what we called psychological kidnapping to explain this process.

\section{PILOT STUDY}

The purpose of the pilot study was to explore corruption behaviours in China and to extract the core psychological characteristics of corrupt officials. The results were to be used as a reference criterion for selecting and analysing materials for the studies to follow, which aimed at exploring the behavioural mechanisms of corruption. This 
was the most important part of constructing the proposed psychological kidnapping model (Xu, 2011).

\section{Method}

The researchers in this study read and discussed available corruption cases found in public newspapers and magazines published from 2007 to 2011. The discussion was designed to extract common psychological features of Chinese officials' corruption.

\section{Results}

Through generalising from common characteristics of these corruption cases, we decided to focus on the following characteristics.

\section{The Phenomena of How a Good Official Becomes Corrupt}

There are many forms of corruption, and these are also found in the characteristics of corrupt officials. The focus of this study was particularly on officials who were innocent and upright to begin with yet gradually became corrupt. The motivations of corrupt officials appeared twofold: (1) We selected the group of 'good officials' instead of 'rent-seekers', because rent-seekers aim at seeking benefits and using public power for their own interests, which can be prevented by careful selection, whereas the 'good-at-beginning' officials become passively involved in corruption cases due to external influence from relationship with others. The stage of 'becoming corrupt' can be prevented by monitoring and supervision, which has important practical implications for policy making. (2) Psychologically, it is useful to study the process of how corruption occurs and develops as it can help identify the features of corruption mechanisms in social interactions.

\section{The Interaction Process in Corruption}

Corruption is an interactive behaviour. Most corrupt behaviours require two parties, namely the briber and the bribee (or petitioner and allocator). Deviating from the assumption of isolated individuals socialising to make rational decisions on the basis of self-interest in the West, the norms of reciprocity shaped by the hierarchical relationalism are intense in a Chinese context (Hwang, 1987; Liu, Yeh, Wu, Liu, \& Yang, 2015). Both expressive and instrumental features of the relationship between the two parties change gradually through interactions.

\section{The Conditions for Carrying Out Corruption}

The process by which officials become corrupt is gradual. The bribee feels comfortable at the beginning, as with the frog swimming in warm water, unaware of the risk. After receiving many small-value 'gifts' from the briber, when being asked to allocate public resources unfairly, the bribee is likely to become aware of the danger. However, by this time, they have already been trapped and have no chance of escaping from a deeply embedded social reciprocal dilemma.

\section{STUDY 1}

The purpose of study 1 was to explore and identify the mechanisms and the interactive process by which good officials becoming corrupt.

\section{Method}

First, we chose cases from magazines such as Qiu Shi (求 实), published by the Communist Party of China's (CPC) school in Jiangxi Province, which studies major issues in contemporary China at both theoretical and practical levels, and from Ji Jian Gong Zuo (纪检工作), published by the CPC Central Committee, which gives a comprehensive summary of the party's disciplinary inspections at the grassroots level. Only those cases that met the three standards established in the pilot study were selected: (1) the cases of a 'good official becomes corrupt', (2) the case materials that included the description of the social interaction between the bribed official and the briber, (3) the case materials that included the reasons why corruption happened. A total of 38 cases were selected and analysed.

Second, we categorised and coded the materials based on elements such as the characteristics of the bribers and the bribees respectively (e.g., their attitudes and principles, existing resources, interpersonal relationships and official behaviours), the premises (the cause of corruption, such as guanxi, threat, and so on), the key points (the tipping points throughout the course of the case), and the results of establishing the relationship, including accepting or rejecting the petitioners' demands in each case. In this process, a descriptive model was established.

Third, based on the model established from the case studies, we formalised an outline and separately interviewed two former officials who were in charge of disciplinary inspections and supervision for the CPC. The purpose of the semistructured interviews was to verify and modify the descriptive model of psychological kidnapping. An analysis was conducted through a three-step coding process. The first step was to obtain meaningful units such as words and sentences from the interviews and define them conceptually. The second step was to group the meaningful units with similar meanings into one category and record the frequency of the units into one large category (Hsieh \& Shannon, 2005). The final step was to conclude core categories and move toward a conceptual framework (Drever, 1995; Galletta \& Cross, 2013).

\section{Results}

\section{The Definition of Psychological Kidnapping}

Based on the case studies, discussions, and interviews, we found an interesting phenomenon in bribery cases within the context of Chinese culture, which was defined as $p s y$ chological kidnapping. Psychological kidnapping is defined as a process in which the kidnapper, in order to attain his/her desired benefits and instrumental goals, develops an affective bond with the kidnapped, who gradually 
lowers defences and risk perceptions, allowing the kidnapper to use the established relationship to get special considerations and help from the kidnapped. The core of psychological kidnapping is the renqing dilemma (reciprocity).

\section{The Character of Psychological Kidnapping}

Relationship change in psychological kidnapping. One of the key elements in a successful kidnapping is the discrepancy in interpretations of the relation between the two people involved in the relationship. In the initial stage of the relationship, the kidnapper has a tendency to use expressive ways of communication that can be rendered as an individual's feelings of affection, warmth, safety, and attachment (Hwang, 1987) without revealing any instrumental intention. In the relationship consolidating stage, the kidnapper aims to gain the trust of the kidnapped by following the rule of expressive interaction. At these two stages, the kidnapped interprets the relationship as an expressive tie. However, in the next stage, when the kidnapper starts to use the relationship (i.e., renqing) for gaining public resources, the instrumental intention is revealed, and the kidnapped official is likely to feel forced to comply. At this point, if the kidnapped official interprets the relationship as a mixed tie, s/he is likely to be caught in a renqing dilemma; if the kidnapped interprets the relation as merely instrumental, s/he can instead formalise a benefit exchange relation with the kidnapper and become a rentseeker. Then, the kidnapped becomes vulnerable and passive, while the kidnapper becomes mighty and positive. As the former Beijing Haidian District mayor, a corrupted official said: 'After I had the power, the circle of my friends began to change. Many of my mistakes were caused by the organisation of my friends, they loved me but also hurt me.'

Subjects of psychological kidnapping. The subject positions involved in the psychological kidnapping process are metaphorically the kidnapper and the kidnapped. The kidnapper is the briber (or the petitioner), such as a business person or an interest group. The kidnapped one is the bribee (or the resource allocator), such as an official in public service. The purpose of the kidnapper in establishing a link with the kidnapped is to obtain public resources. They need to establish a secure expressive relationship, because in Chinese social life, social relations spread out gradually, from individual to individual, resulting in an accumulation of personal connections (chaxugeju 差序 格局: differential modes of association); morality makes sense only in terms of these personal connections (Fei, 1992). Chinese people often do not have a clear distinction between 'public' and 'private', but only make the judgment in accordance with social distance and closeness of interpersonal relationships (Yang, 1995). Therefore, when the relationship between the two turns from strangers to friends, the kidnapped ones usually lower their risk perception and offer help to the petitioners. For example, the former director of Lin Hai Cultural Broadcasting Press and Publication Bureau was very down to earth and hardworking at the beginning of his political life. Because he liked orchids, some people met him in the name of 'using orchids to make friends.' They continuously gave him precious live orchids as presents, and then became good friends due to the hobby. So, he helped those people who shared 'friendship guanxi' with him by using his power in their favour in spite of the law. This shows how he lowered his defences and eventually fell into the quagmire of corruption.

Realisation of psychological kidnapping. The process of being psychologically kidnapped is exactly the same as the 'boiled frog' syndrome. If you put a frog into a pan of cold water and turn on the heat, the frog will happily sit there without noticing that the water is getting hot, resulting in death. The kidnapped would feel comfortable at the beginning by enjoying the favour and expressive care offered by the kidnapper without consciousness of the potential danger. For example, the former deputy director of the Chongqing Police Bureau attributed his falling into corruption to 'falling into the trap of boiled frog, I didn't have any ability to struggle when I finally realised it'. Also, the former communications bureau chief of Wushan County in Chongqing was regretful of making friends with people who had evil intentions, and said: 'They [the friends] would pull me by a leash once I fell into their trap.'

The most important characteristic of the boiled frog syndrome is the imbalance between risk perception and the cost of rejecting the kidnapper's demands for the kidnapped. Risk perception is lowered by the kidnapper's affectional investment in the relationship and rejection costs, such as the renqing norm, sense of indebtedness, payback cost, and risk of whistle-blowing, which keep increasing as long as the kidnapped continues to accept affectional seduction from the kidnapper. Then the official falls into a coerced situation without even being aware of the danger.

\section{The Interaction Process Model of Psychological Kidnapping}

The psychological kidnapping process is a series of interactions between the kidnapper and the kidnapped. We built the descriptive model through analysing the key elements and junctures of the kidnapping process, such as the transformation point, psychological strategies, and risk perception (see Figure 1).

In the process of psychological kidnapping, the kidnapper actively seeks to build a relationship with those who have the authority to allocate resources. At an early stage, the kidnapper uses a series of psychological strategies to establish a close relationship with the kidnapped. The kidnapped accepts and gradually becomes accustomed to the behaviour of the kidnapper, without being conscious of the true instrumental intentions of the kidnapper. The guanxi will change from strangers to close 'friends'. Later, the kidnapper will use affectional blackmail, such as 'we are friends and you should help your 


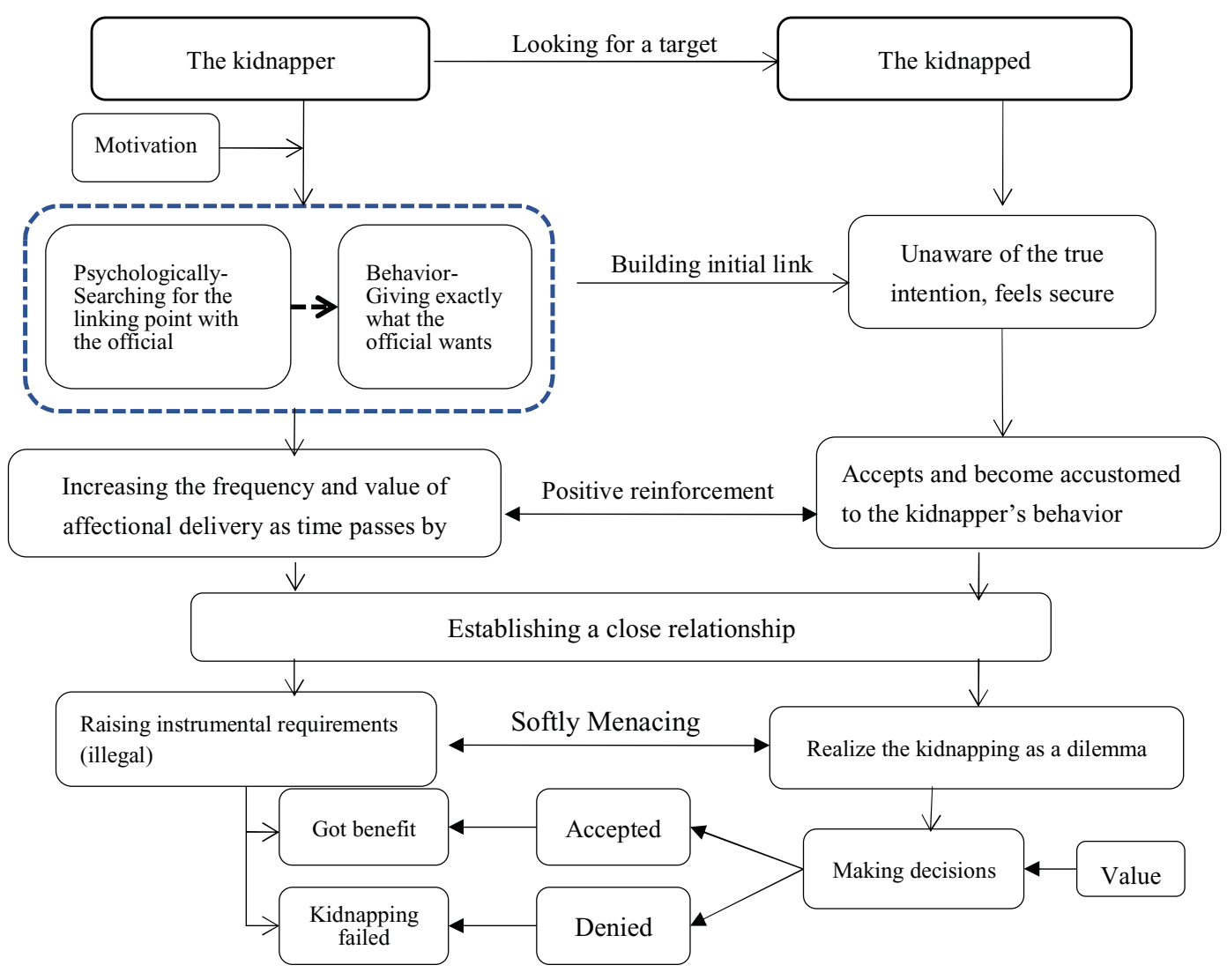

Figure 1

Model of psychological kidnapping.

friends' to softly menace the kidnapped to corruption. When the kidnapped realises the true intentions of the kidnapper, the guanxi has been already established and the kidnapped is trapped in a renqing dilemma. If the kidnapped treats civic rights as personal, s/he would accept the demands from a 'friend' and become involved in corruption. However, if the kidnapped does not want to violate the principle of law and denies the demands from a friend (as a social network is a framework for evaluating the behaviour of people in appropriate situations; Barnes, Boissevain, \& Mitchell, 1975), s/he may face the risk of being condemned or rejected, because when interacting with other people, one should start with an assessment of the relationship between oneself and others along two cognitive dimensions: intimacy/distance and superiority/inferiority. Instead of treating everyone with equal affection, according to the Confucian idea of benevolence, one should consider the principle of favouring the intimate (Hwang, 2001). The decision would depend on the judgment of risk and benefits.

\section{STUDY 2}

The purpose of study 2 was to sum up the characteristics and process of 'good officials becoming corrupted' and to confirm the psychological kidnapping model.

\section{Method}

\section{Sample}

A theoretical sampling method was used, which meant choosing the group and materials that could answer the most important questions of timing, scene, and participants for the issues of concern (Weiss, 1995). With psychological kidnapping, the concern is why good officials 'fall into' corruption. Therefore, the sampling process was conducted through openly published interviews of corrupt officials who were convicted within the nearest decades under the sampling frame of (1) non-rent-seeking officials, (2) the materials should depict the changing process of the official from incorruptible to corrupted, and (3) focusing on the role of renqing during the interaction between the official and the kidnapper. Under this framework, 19 cases were found suitable for the research purpose. The characteristics of these cases included: (1) the sources - the cases were from both government websites such as Xinhua Web, and non-government websites such as Phoenix Net or Tencent Net ${ }^{1}$; (2) the region - the officials in these cases were from 12 provinces; (3) the positions - the officials worked in party and government offices, public institutions, or state-owned enterprises; (4) the rankings - the officials were from bureau to departmental level, mainly departmental or deputy departmental level. 


\begin{tabular}{ll}
\hline $\begin{array}{l}\text { Table } \mathbf{1} \\
\text { Text Analysis of Coding }\end{array}$ & \\
\hline Coding category & Coding content \\
\hline Identity coding & $\begin{array}{c}\text { The identity and characteristics of } \\
\text { official } \\
\text { The identity and characteristics of } \\
\text { briber } \\
\text { The stage of relationship } \\
\text { establishing } \\
\text { The stage of relationship } \\
\text { consolidating } \\
\text { The stage of relationship using } \\
\text { The stage of relationship } \\
\text { terminating } \\
\text { The characteristics of interaction } \\
\text { between the two sides }\end{array}$ \\
Characteristic analysis & \\
\hline
\end{tabular}

\section{Coding}

Grounded theory was used in the coding, which is a widely used qualitative research technique (Hsieh \& Shannon, 2005; Stemler, 2001) aimed at developing theories inductively from data, rather than testing existing theories or generating only themes (Service, 2009; Strauss, 1987). Three analysing perspectives were established according to the phenomenal model of psychological kidnapping: identity analysis, process analysis, and characteristic analysis. See Table 1.

There were three steps in the coding: open coding, axial coding, and selective coding. In open coding, data is read word by word to derive codes (Huberman \& Miles, 1994) and capture key thoughts or concepts. We decomposed the text of the interviews into separate sentences, phrases or words, maintaining the units relevant to the question or phenomenon we were interested in. Then we grouped units with the same connotations, forming and naming new units (a1, a2, a3 ...). To avoid the subjective bias of the coders, the coding of step 1 was done separately by four coders. Open coding extracted 148 units.

In axial coding, codes were sorted into categories based on how different codes were related and linked (Coffey \& Atkinson, 1996). Researchers integrated the units identified in step 1, then organised and grouped them into meaningful units. Through this process, the scattered words or phrases could be collected and linked to each other, laying a foundation for the next coding step. The categorical units formed in this step were named by the capital letter 'A', as A1, A2, and so on; 21 categorical units were selected from this stage.

In selective coding, core units were chosen from 21 categorical units from the axial coding stage, named as B1, B2, and so on. The other units were gradually gathered around the core units (see Table 2). There were 11 second level categorical units that emerged through comparison and combination (B), which were divided into four groups: the official's character (B1-3), the official's psychological process (B4-5), the resource's character and delivery (B6-10), and the resources output process ending (B11). These secondary categories could be analysed from three possible perspectives: identity analysis, process analysis, and characteristic analysis.

\section{Analysis \\ Identity Analysis}

The results of data analysis showed that throughout the course of interactions between the briber and the official, the official's identity was consistent with that of a kidnapped individual, as the risk alert level decreased and the sense of menace appeared; while the briber's identity was consistent with that of a kidnapper, featuring resource delivery in the form of returned favours for instrumental purposes.

The kidnapper and the kidnapped have different characteristics in the kidnapping relationship. As the psychological kidnapping model shows, the kidnapped is honest, innocent and competent (B1) with no intention of rent-seeking at first (A1/2/3). Many people are attracted by the power of allocating public resources (B2) to build relationships with him/her (A11). At the same time, the official is in need of some personal resources that cannot be obtained by himself/herself (B3). Once the official accepts the personal resources delivered by the kidnapper, the perception of risk may decrease (B4) and the resources would be interpreted as renqing or favour instead of briberies (B6). However, when the 'friend' begins to ask for payback by requesting an unfair allocation of public resources, the official would feel a sense of being compelled (B5) and be trapped in dilemmas that place him/her in difficult moral predicaments, requiring him/her to weigh whether the moral end (helping friends) can justify the immoral means (corruption). Chinese people tend to rely on relationship orientation when they encounter moral judgments (Wei \& Hwang, 1998). The renqing rule emphasises that once an individual receives a favour from others, s/he is obligated to reciprocate in the future. Refusing the kidnapper's request will result in a breakdown of mutual affection (ganqing polie, 感情破裂) and the kidnapped will be despised by other guanxi members as dishonest or lacking human feelings (Wang, 2016). Therefore, the cost of saying 'no' to those who share strong ties is high.

On the other hand, the briber (kidnapper) depicts a self-image of being honest, considerate, and reliable at the beginning. During the relationship establishing process, s/he shows affection on the surface but has a hidden instrumental purpose (B8). Most of the gifts (including the emotional support) are delivered uninterruptedly from the kidnapper with high frequency, satisfying the need of the kidnapped with high personalisation, but nothing is asked for in return (B7). After gradual material delivery and emotional expression (B10), the guanxi bondage is formed. See Table 3. 
Table 2

Coding, Categorical and Core Units in all 19 cases

\begin{tabular}{|c|c|c|c|c|c|}
\hline Coding & Categorical units & Frequency & Coding & Core units & Frequency \\
\hline A1 & $\begin{array}{l}\text { The official was honest and competent at the } \\
\text { beginning }\end{array}$ & 13 & B1 & $\begin{array}{l}\text { The official was honest and competent at } \\
\text { the beginning }\end{array}$ & 17 \\
\hline A2 & $\begin{array}{l}\text { The official was alert to the gifts and treats at the } \\
\text { beginning }\end{array}$ & 3 & & & \\
\hline A3 & The official was not rent-seeking at first & 1 & & & \\
\hline A4 & The official had a large amount of power & 4 & B2 & The official was with power & 4 \\
\hline A5 & The official was in need of resources (e.g., money) & 13 & B3 & The official had certain need & 17 \\
\hline A6 & The official was self-aggrandizing & 4 & & & \\
\hline A7 & The risk perception of the official was reduced & 12 & B4 & $\begin{array}{l}\text { The risk perception of official went down } \\
\text { after making friends with the kidnapper }\end{array}$ & 14 \\
\hline A8 & $\begin{array}{l}\text { The official was not alert to the resources delivery } \\
\text { of a friend }\end{array}$ & 2 & & & \\
\hline A9 & $\begin{array}{l}\text { The official cannot get rid of the relationship so } \\
\text { that s/he must accept the requirement }\end{array}$ & 9 & B5 & $\begin{array}{l}\text { The official had a sense of menace and } \\
\text { unable to reverse the relationship }\end{array}$ & 18 \\
\hline A10 & $\begin{array}{l}\text { The official found the delivery of resources hard to } \\
\text { resist }\end{array}$ & 4 & & & \\
\hline A11 & $\begin{array}{l}\text { The relationship would not end once it began, and } \\
\text { the network of "friends" would become bigger } \\
\text { A11 }\end{array}$ & 5 & & & \\
\hline A12 & $\begin{array}{l}\text { The official interpreted the personal resources as } \\
\text { renqing }\end{array}$ & 21 & B6 & $\begin{array}{l}\text { The official interpret the resources } \\
\text { delivered by the kidnapper as renqing }\end{array}$ & 21 \\
\hline A13 & The resources were highly personalized & 12 & B7 & $\begin{array}{l}\text { The resources were delivered } \\
\text { frequently/personalization /asymmetric }\end{array}$ & 23 \\
\hline A14 & The resources were delivered with high frequency & 6 & & & \\
\hline A15 & $\begin{array}{l}\text { The resources were delivered unilaterally from the } \\
\text { kidnapper to the official }\end{array}$ & 5 & & & \\
\hline A16 & The resources were with instrumental purpose & 6 & B8 & $\begin{array}{l}\text { The affectional deliveries were with } \\
\text { instrumental purposes }\end{array}$ & 24 \\
\hline A17 & $\begin{array}{l}\text { The instrumental investments were catering to the } \\
\text { official's pleasure }\end{array}$ & 12 & & & \\
\hline A18 & $\begin{array}{l}\text { The kidnapper sometimes exchanged affectional } \\
\text { resources with the official }\end{array}$ & 6 & & & \\
\hline A19 & The deliveries were of all kinds & 5 & B9 & The resources delivered were various & 5 \\
\hline A20 & $\begin{array}{l}\text { The value of the resources delivered was gradually } \\
\text { increased }\end{array}$ & 3 & B10 & The resources were delivered step by step & 3 \\
\hline A21 & $\begin{array}{l}\text { The resource delivery stopped as the power of the } \\
\text { official ended }\end{array}$ & 2 & B11 & $\begin{array}{l}\text { The delivery process ends with loss of } \\
\text { losing power by official }\end{array}$ & 2 \\
\hline
\end{tabular}

Table 3

The Kidnapper and The Kidnapped's Characteristics

\begin{tabular}{|c|c|c|c|c|}
\hline Roles & Features & About the truth & Relative status & Psychological reactions \\
\hline $\begin{array}{l}\text { The official who has been } \\
\text { kidnapped }\end{array}$ & $\begin{array}{l}\text { Has resources, has power, has } \\
\text { the ability to succeed, weak } \\
\text { resistance to temptation, good } \\
\text { performance, be loyal to } \\
\text { friends }\end{array}$ & $\begin{array}{l}\text { Knows nothing about the } \\
\text { truth at the beginning }\end{array}$ & Mighty $\rightarrow$ weak & $\begin{array}{l}\text { Psychological dilemma, } \\
\text { thinking about owing } \\
\text { others }\end{array}$ \\
\hline Kidnapper & $\begin{array}{l}\text { Purposive, honest, steady-going } \\
\text { and reliable surface } \\
\text { impression, good at catching } \\
\text { hold of opportunities, } \\
\text { interpersonal sensitivity }\end{array}$ & Knows the truth & Weak $\rightarrow$ mighty & The exchange of power \\
\hline
\end{tabular}

\section{Process Analysis}

The process of psychological kidnapping can be divided into three stages. See Table 4.

Stage 1: Attraction and acceptance. At this stage, the kidnapper's main goal is to establish a relationship. The official who has the power of allocating public resources (B2) is competent and a non-rent-seeker. The kidnap- per delivers both material resources (personalised gifts) and emotional support to establish a relationship with the official (B7/9/10). As the former director of Wu Shan Transportation Bureau said: "We [with the kidnapper] just talked about our families that day. We found that we shared some common interests and we both were very pleased. I thought Zhou could be a great friend. And Zhou never mentioned the topic of contracting 


\begin{tabular}{|c|c|c|c|c|}
\hline Stages & Behavior characteristics & Informed situation & Relative position & Psychological reflection \\
\hline $\begin{array}{c}\text { Attraction and } \\
\text { acceptance }\end{array}$ & $\begin{array}{l}\text { Bilateral selection, searching for } \\
\text { common linking point, } \\
\text { middlemen introduce }\end{array}$ & $\begin{array}{l}\text { The kidnapper: informed } \\
\text { The kidnapped: } \\
\text { some information }\end{array}$ & $\begin{array}{l}\text { The kidnapper: weak } \\
\text { The kidnapped: mighty, } \\
\text { holding dominant right } \\
\text { of relationship }\end{array}$ & Interpersonal attraction \\
\hline Trust and integration & $\begin{array}{l}\text { The kidnapper: satisfy official's } \\
\text { need, resource output, } \\
\text { potential resources exchange } \\
\text { The kidnapped: } \\
\text { Acceptance, habituation }\end{array}$ & $\begin{array}{l}\text { The kidnapper: Informed } \\
\text { The kidnapped: knew } \\
\text { nothing }\end{array}$ & $\begin{array}{l}\text { The kidnapper: from weak } \\
\text { to mighty } \\
\text { The kidnapped: from } \\
\text { mighty to weak }\end{array}$ & $\begin{array}{l}\text { Trust; } \\
\text { renqing delivery, } \\
\text { risk perception }\end{array}$ \\
\hline Collusion or fracture & $\begin{array}{l}\text { The kidnapper: soft menace, } \\
\text { revenge } \\
\text { The kidnapped: obey or refuse }\end{array}$ & Both sides were informed & $\begin{array}{l}\text { The kidnapper: mighty } \\
\text { The kidnapped: weak }\end{array}$ & $\begin{array}{l}\text { The kidnapper: power } \\
\text { relationship changing } \\
\text { The kidnapped: dilemma }\end{array}$ \\
\hline
\end{tabular}

the project, which made me more determined about my own ideas."

Stage 2: Trust and integration. At this stage, the relationship is strengthened continually. The official starts to accept the resources delivered by the kidnapper without noticing the true purpose of the kidnapper. The official is likely to evaluate the relationship as expressive ties (B6) based on the kidnapper's delivery style, such as high frequency and affectional influence, without asking any payback (B7/B9/B10); the perceptions of risk may decrease (B4).

Stage 3: Collusion or fracture. After a while, when the kidnapper feels that the relationship has been consolidated, s/he may make a request to use the official's power for allocating public resources as a favour (B8). At this time, the official cannot resist the request because of the favours (renqing) $s /$ he owes to the kidnapper. Thus, the corruption begins (B5). The relationship will terminate if the official has retired or been investigated. The kidnapper would then stop delivering resources as soon as the official lost his/her power (B11).

\section{Characteristics Analysis}

The characteristics of psychological kidnapping can be summed up in terms of eight components: precondition, means, kidnapping point, psychological process, results, types, functions, and forms.

Precondition. First, the kidnapper uses affectional investments to establish a safe and reliable interpersonal relationship. The kidnapper delivers resources to the official from the beginning without asking for anything in return, which is strongly asymmetric regarding the reciprocal expectations. Second, the official is passive (A9). The official may feel a sense of 'being led by the friends' (B5), which means s/he has to obey her/his friends' requirements, with a lower sense of authority and control, and more stress. It is a mutual selection process, with the kidnappers searching for officials who are easily enmeshed and the officials searching for people who can be true friends.
Means. From the start, the kidnapper aims to provide what the official likes or needs, be it hobbies, inexpensive collections, or assistance for family members. Affective interactions will increase the dependence of the kidnapped on the kidnapper.

The kidnapping point. The relationship between the kidnapper and kidnapped transforms from defensive (A8) to hard-to-refuse (A9). The early investment turns into benefits and who has the initiative changes. The kidnapper seeks a greater influence over the kidnapped to obtain the power controlled by the kidnapped. The turning point is when the kidnapped official feels safe about the relationship and the kidnapper feels that it is an appropriate time to make a request.

Psychological process. As mentioned in the identity analysis, the kidnapped official's risk perception declines step by step and the cost of rejecting the kidnapper's demand increases.

Results. There are two possible results of psychological kidnapping. First, the kidnapping is successful. Under this situation, the kidnapped accepts the requirements, so the kidnapper gains the benefits and rewards s/he has wanted, such as getting investment illegally or a job through the official's power, in order to take a shortcut. Second, the kidnapped refuses the requirements, so the relationship may be damaged. Under this situation, 'revenge' (i.e., whistleblowing) may occur.

Types, functions, and forms. The types of psychological kidnapping are various, including political, economic, and affectional (family, marriage). The functions of psychological kidnapping are to protect oneself, gain resources and take advantage of others' influence. There are two forms: (1) Direct kidnapping, which happens only between the kidnapper and the official who is kidnapped. In other words, the petitioner only 'makes friends' with an allocator to establish the expressive tie. (2) Indirect kidnapping, when the kidnapping happens among the kidnapper and the people around the official who is kidnapped, such as when the petitioner ingratiates him/herself with the allocator's spouse, children, other family members, and staff. 


\section{Outcomes}

\section{Process of Psychological Kidnapping}

The psychological kidnapping process contains three main stages. In the first stage, the kidnapper initiates the relationship with the official by searching for a common link and starts to deliver resources to the official. In the second stage, as the relationship develops, the trust between the two parties is formed and a close tie is established. At this point, the kidnapper asks for almost nothing in return but continues to deliver resources to the official in order to strengthen the relationship. In the third stage, the kidnapper attempts to gain benefits by accessing the official's political power, perhaps through soft menace. At this point, the official has been subtly coerced to seize public resources on behalf of the kidnapper. It also includes the end stage, where the official loses power and the kidnapper stops delivering resources.

\section{Characteristics of Psychological Kidnapping}

There are three main characteristics of psychological kidnapping: (1) Concealed delivery, which is when the kidnapper hides his/her true purpose at the beginning by being nice to the official and delivering resources as affectional investments and which may give the official a sense of security. (2) Risk and cost imbalance, when the official's perception of risk is reduced by the affectional tie established through expressive resource deliveries by the kidnapper. However, the cost to resist the kidnapper's request keeps increasing, creating a cognitive dissonance, sense of indebtedness, possible damage to the social network, or the possibility of whistle-blowing, and thus the risk and cost become imbalanced. (3) Soft menace, which means that the kidnapper may use soft factors such as relationship, favour or stress to force the official to accept the request instead of overt violent menace. For example, an official said: 'Whatever difficulties I encounter in my family, they [the friends] are always eager to help me. And when it comes to working together with them to make money, I cannot say no to them.'

\section{Essence of Psychological Kidnapping}

As a special tie, the mixed tie between the kidnapper and the kidnapped contains both an expressive component and an instrumental component. There is no obvious boundary between the components in Chinese culture. In an attempt to reach his instrumental goal, an individual sometimes establishes expressive ties with powerful others. However, it takes time for such a tie to form; therefore, it is necessary to hide the instrumental purpose before the relationship has been established, so the kidnapped is unaware of the truth and the danger. The kidnapper uses the expressive tie as an instrument to procure the desired material resources. As an official recalled: 'Mr Zhou never mentioned contracting the project, which helped deepen our friendship. One day in 2003, when my daughter was about to start her university in another city, Zhou told me that he rented an apartment for my daughter right next to her school so that she could live nearby. I was so moved by his consideration and accepted this gift.... In early 2006, many roads in Wushan needed reconstruction. Zhou, who never asked any favour from me before, suddenly visited me, proposing to contract the project.' During this process, their relationship changed from an expressive tie to an instrumental tie for the official who was kidnapped.

\section{General Discussion}

The current research used qualitative analyses method to study corruption cases and interviews with the authorities in question, to answer the question of how good officials become corrupt in a Chinese cultural context. By analysing the sequence and key points of the psychological kidnapping process, the researchers summarised the characteristics of the corrupt officials involved and the interpretation of their relationship. The concept and model of psychological kidnapping were raised as a result, which may provide a foundation for future studies on corruption psychology in Chinese culture.

There are some conditions for successful psychological kidnapping. The first and foremost is the dominance of the renqing principle. In Chinese culture, the rule of renqing is a derivative of the norm of reciprocity, which guides the social exchange of resources in the mixed tie (Buckley, Clegg, \& Tan, 2006; Lu, 2012; Yang \& Wang, 2011). To ordinary people, Chinese ethics have a practice of such maxims as 'do not forget what other people have done for you (知恩图报)'. After helping the official, the kidnapper can rightly look forward to a return, because a reciprocal action cannot be neglected by the official when the kidnapper is in 'need' (Hwang, 1987). In other words, a public official may receive certain types of favours from others in a guanxi network, such as getting assistance when encountering a difficulty. These favours thus cultivate a sense of obligation on the part of the kidnapped, who is willing to find ways to pay back the favour by using her/his resource allocation power. The reciprocity is so important that it helps to maintain the balance of the relationship, otherwise it may bring disgrace to the official's close associates.

Another condition is the guanxi orientation (or relationalism). In China, guanxi prescribes different sets of rules for identifying and dealing with in-groups and outgroups (Chib, Phuong, Si, \& Hway, 2013). According to the renqing rule, people should maintain a good guanxi, which is a complex construct of interpersonal interactions (Bell, 2000; Chen \& Chen, 2004; Chou, Cheng, Huang, \& Cheng, 2006; Kriz, Gummesson, \& Quazi, 2013), with others in the ties mix. The normative function of a guanxi network is to enhance the opportunities, means, and incentives for public officials to engage in corruption (Zhan, 2012), which means that the principle of reciprocity (bao, 报) and the norm of gift-giving (songli, 送礼) could encourage government officials to meet the demand from guanxi networks, regardless of the legal norms designed 
by the state authority. When an individual's interpersonal behaviour is in violation of the renqing rule, his/her feelings of guilt may be initiated (Feng, Xu, Long, \& Zhang, 2015). Taking the norm of gift giving into account, the official who is kidnapped will feel shame and guilt if s/he refuses the petitioner's requests (Hwang, 1987). The norm of gift giving in a guanxi network helps bring down a major barrier to relationship establishment in corrupt cases $(\mathrm{Li}$, 2011). Guanxi networks normalise corrupt transactions through the neutralisation process (Wang, 2016), where the bribees use it to justify their behaviours and lessen their responsibilities.

Third, it is crucial for Chinese people to manage his/her self-image and maintain mianzi in front of others $(\mathrm{Hu}$, 1944; Hwang, 1987; Servaes, 2016), or what is called 'face work'. The kidnapped should 'give mianzi (给面子)' to the kidnapper in order to exchange renqing (Zhai, 2005). Face is lost when the individual fails to meet essential reciprocal requirements (Ho, 1976). If the official helps the kidnapper, they will both feel enhanced in social status and high self-esteem (you mianzi, 有面子). However, if the official refuses to help, he/she will make the kidnapper 'lose mianzi(丢面子)', which may cause him/her suffering uneasiness in the long run. As an official recalled:

I embarked on the road to crime in 2002. One afternoon, a Jinan economic and trade company staff $\mathrm{Mr}$ Chen asked me to help him by signing an import car quota. I did not agree at the beginning, because I was not in charge of the work... But I had a good impression of his classmate Mr Wang, so Chen let Wang come to me again and again to ask for the favour.... Later, to give Wang a mianzi, I signed my name on the report by the company to the provincial Economic and Trade Commission Office.

Last, but not least, as an old proverb goes, 'The barefoot is not afraid of that in shoes', so the kidnapped officials are worried about their own benefits. They want to keep their honour and high status as a government employer, while the kidnappers have barely anything to lose. Moreover, in some cases of psychological kidnapping (such as political cases), refusing the requirements means fighting against a stronger invisible power which may lead to self-destruction.

The research about psychological kidnapping phenomena will have some practical value in constructing an 'unwilling-to corrupt' society. In the practice of reducing corruption in China, President Xi Jinping proposed to focus on creating a political atmosphere of 'dare-not-to (不 敢腐), unable-to (不能腐) and unwilling-to corrupt (不 想腐)' in the Fifth Plenary Session of the 18th CPC Central Committee, which has pointed out the direction for the current anti-corruption campaign (Liao, 2009). The major threat of corrupt transactions is the risk of punishment (Lambsdorff, 2002b). At the dare-not-to stage, a harsh punishment should be imposed on corruption to enhance the risk perception of officials. Because guanxi can facilitate corrupt transactions (Bian, 1997; Wang, 2014, 2016) at the unable-to stage, setting up clear rules of social in- teraction is one way to evade the trouble of renqing as a pathway to corruption. Institutions should perfect and reinforce monitoring, such as being transparent. At the unwilling-to stage, the government should foster officials' factual beliefs about the inherent immorality of corruption (e.g., the autonomous immoral disposition of corrupt officials) and justice analysis of cost-benefits between renqing and the law. Even reading essays about the morality of an action can change readers' beliefs about its costs and benefits (Liu \& Ditto, 2013). In addition, civil servants' awareness of separating instrumental goals from expressive ties should be raised and strengthened by the government.

This study also had a few limitations. First, cases were all gathered from openly published interviews from magazines and newspapers, which might be influenced by political factors. Second, just as with other social characters, the officials were likely to shirk their responsibility in corruption by blaming circumstances or other persons for bad outcomes (Sedikides, Campbell, Reeder, \& Elliot, 1998). People tend to restructure their actions to appear less harmful and minimise their role in the outcomes of their actions, or attenuate the distress that they cause to others in moral disengagement (Bandura, 1999; Bandura, Barbaranelli, Caprara, \& Pastorelli, 2002). By blaming the kidnappers, the officials could retain some shred of morality for themselves and offer kidnapping as an excuse for corruption. Third, besides renqing, there may also be other social relationship concepts such as favour and face involved in the corruption interactions in Chinese culture society (Hwang, 1978). Therefore, other explanations need to be explored in the future.

\section{Conclusion}

A concept and model of psychological kidnapping was developed to answer the question of how good officials become corrupt. The process of psychological kidnapping includes three stages: attraction and acceptance, trust and integration, and collusion or fracture. The concealed delivery of resources, the imbalance of the official's risk and cost perceptions, and soft menace from the kidnapper are three important characters defining psychological kidnapping. Renqing plays an essential role in the process of psychological kidnapping.

\section{Acknowledgments}

The authors are grateful to the editor and two anonymous reviewers for their constructive comments, and to the researchers who participated in the coding process.

\section{Endnote}

1 Xinhua Web: Xinhua Wang in Chinese, http://www. xinhuanet.com/; Phoenix Net: Fenghuang Wang in Chinese, http://www.ifeng.com/; Tencent Net: Tengxun Wang in Chinese, http://www.qq.com/ 


\section{References}

Bandura, A. (1999). Moral disengagement in the perpetration of inhumanities. Personality and Social Psychology Review, 3, 193-209.

Bandura, A., Barbaranelli, C., Caprara, G.V., \& Pastorelli, C. (2002). Mechanisms of moral disengagement in the exercise of moral agency. Journal of Moral Education, 31, 101-119.

Barnes, J.A., Boissevain, J., \& Mitchell, J.C. (1975). Network analysis: studies in human interaction. American Journal of Sociology, 26, 67-71.

Bedford, O. (2011). Guanxi-building in the workplace: A dynamic process model of working and backdoor guanxi. Journal of Business Ethics, 104, 149-158.

Bell, D. (2000). Guanxi: A nesting of groups. Current Anthropology, 41, 132-138.

Bian, Y. (1997). Bringing strong ties back in: Indirect ties, network bridges, and job searches in China. American Sociological Review, 62, 366-385.

Buchanan, J., Tullock, G., \& Tollison, R. (1983). Toward a theory of the rent-seeking society. Public Choice, 41, 339-345.

Buckley, P.J., Clegg, J., \& Tan, H. (2006). Cultural awareness in knowledge transfer to China - The role of guanxi and mianzi. Journal of World Business, 41, 275-288.

Cameron, L., Chaudhuri, A., Erkal, N., \& Gangadharan, L. (2009). Propensities to engage in and punish corrupt behavior: Experimental evidence from Australia, India, Indonesia and Singapore. Journal of Public Economics, 93, 843-851.

Chen, X.P., \& Chen, C.C. (2004). On the intricacies of the Chinese guanxi: A process model of guanxi development. Asia Pacific Journal of Management, 21, 305-324.

Chib, A., Phuong, T.K., Si, C.W., \& Hway, N.S. (2013). Enabling informal digital guanxi for rural doctors in Shaanxi, China. Chinese Journal of Communication, 6, 62-80.

Chou, L.F., Cheng, B.S., Huang, M.P., \& Cheng, H.Y. (2006). Guanxi networks and members' effectiveness in Chinese work teams: Mediating effects of trust networks. Asian Journal of Social Psychology, 9, 79-95.

Coffey, A., \& Atkinson, P. (1996). Making sense of qualitative data: Complementary research strategies. Sage Publications, Inc.

Dai, C. (2013). Corruption and anti-corruption in China: Challenges and countermeasures. In S. Rothlin \& P. Haghirian (Eds.), Dimensions of teaching business ethics in Asia (pp. 61-76). Heidelberg, Germany: Springer.

Deng, X., Zhang, L., \& Leverentz, A. (2010). Official corruption during China's economic transition: Historical patterns, characteristics, and government reactions. Journal of Contemporary Criminal Justice, 26, 72-88.

Drever, E. (1995). Using semi structured interviews in small scale research. Retrieved from https://eric.ed.gov/?id=ED394990

Fei, X. (1992). From the soil: The foundations of Chinese society. Berkeley, CA: University of California Press.

Feng, Q., Xu, Y., Long, Y., \& Zhang, M. (2015). Allocation of social resources 'kidnapped' by the sense of renqing guilt. Journal of Beijing Normal University [in Chinese], (4), 423428.
Galletta, A., \& Cross, W.E. (2013). Mastering the semi-structured interview and beyond: From research design to analysis and publication. Thorax, 13, 222-228.

Goel, R.K., \& Rich, D.P. (1989). On the economic incentives for taking bribes. Public Choice, 61, 269-275.

Guo, Y., \& Li, S. (2015). Anti-corruption measures in China: Suggestions for reforms. Asian Education and Development Studies, 4, 7-23.

Han, R. (2016). Discussion on relationship between guanxi and corruption in China. British Journal of Economics, Management \& Trade, 14, 1-9.

$\mathrm{He}, \mathrm{Z}$. (2000). Corruption and anti-corruption in reform China. Communist and Post-Communist Studies, 33, 243-270.

Ho, D.Y.F. (1976). On the concept of face. American Journal of Sociology, 81, 867-884.

Hsieh, H.F., \& Shannon, S.E. (2005). Three approaches to qualitative content analysis. Qualitative Health Research, 15, 12771288.

Hu, H.C. (1944). The Chinese concepts of 'face'. American Anthropologist, 46, 45-64.

Huberman, A.M., \& Miles, M.B. (1994). Qualitative data analysis: An expanded sourcebook. Thousand Oaks, CA: Sage Publications.

Hunt, J. (2005). Why are some public officials more corrupt than others? NBER Working Paper. https://doi.org/ $10.3386 /$ w 11595

Huntington, S.P., \& Fukuyama, F. (1968). Political order in changing societies: America vs. Europe: New Haven, CT: Yale University Press.

Hwang, K.K. (1978). The dynamic processes of coping with interpersonal conflicts in a Chinese society. Proceedings of the National Science Council, 2, 198-208.

Hwang, K.K. (1987). Face and favor: The Chinese power game. American Journal of Sociology, 92, 944-974.

Hwang, K.K. (2001). The deep structure of confucianism: A social psychological approach. Asian Philosophy, 11, 179204.

Hwang, K.K. (2012a). The construction of the face and favor model. New York: Springer.

Hwang, K.K. (2012b). Foundations of Chinese psychology: Confucian social relations. New York: Springer.

Hwang, K.K. (2015a). Cultural system vs. pan-cultural dimensions: Philosophical reflection on approaches for indigenous psychology. Journal for the Theory of Social Behaviour, 45, $2-25$.

Hwang, K.K. (2015b). Culture-inclusive theories of self and social interaction: The approach of multiple philosophical paradigms. Journal for the Theory of Social Behaviour, 45, $40-63$.

Kriz, A., Gummesson, E., \& Quazi, A. (2013). Methodology meets culture: Relational and guanxi-oriented research in China. International Journal of Cross Cultural Management, 14, 27-46.

Lambsdorff, J.G. (2002a). Corruption and rent-seeking. Public Choice, 113, 97-125. 
Lambsdorff, J.G. (2002b). Making corrupt deals: contracting in the shadow of the law. Journal of Economic Behavior \& Organization, 48, 221-241.

Li, L. (2011). Performing bribery in China: Guanxi-practice, corruption with a human face. Journal of Contemporary China, 20(, 1-20.

Lu, L. (2012). Guanxi and renqing: The roles of two cultural norms in Chinese business. International Journal of Management, 29, 466-476.

Liao, X.H. (2009). Thoughts on preventing and punishing corruption and enhancing construction of party spirit, conduct and discipline. Journal of Shaanxi Administration School [in Chinese], 23, 78-80.

Liu, B., \& Ditto, P.H. (2013). What dilemma? Moral evaluation shapes factual belief. Social Psychological and Personality Science, 4, 316-323.

Liu, J.H.F., Yeh, K.H., Wu, C.W., Liu, L., \& Yang, Y. (2015). The importance of gender and affect in the socialization of adolescents' beliefs about benevolent authority: Evidence from Chinese indigenous psychology. Asian Journal of Social Psychology, 18, 101-114.

Mill, J.S. (1966). On liberty. In A selection of his works (pp. 1-147). London: Macmillan Education UK.

Mishra, A. (2004). Corruption: A review. Journal of Economic Surveys, 15, 71-121.

Montesquieu, C.D.S. (1794). The spirit of laws (vol. 2). P. Dodesley.

Schramm, M., \& Taube, M. (2003, September). On the coexistence of guanxi and a formal legal system in the PR China - An institutionalist approach. In Proceedings of International Society for New Institutional Economics, 7th Annual Conference.

Sedikides, C., Campbell, W.K., Reeder, G.D., \& Elliot, A.J. (1998). The self-serving bias in relational context. Journal of Personality \& Social Psychology, 74, 378-386.

Servaes, J. (2016). Guanxi in intercultural communication and public relations. Public Relations Review, 42, 459464.

Service, R.W. (2009). [Review of the book Basics of qualitative research: Techniques and procedures for developing grounded theory by J. Corbin \& A. Strauss]. Organizational Research Methods, 12, 614-617.

Stemler, S. (2001). An overview of content analysis. Practical Assessment, Research \& Evaluation, 7, 137146.

Strauss, A.L. (1987). Qualitative analysis for social scientists. Cambridge, UK: Cambridge University Press.
Sun, Z., \& Yang, L. (2016). How do anti-corruption efforts affect public perception of corruption? - Evidence from Guangdong province in China. Journal of Public Administration [in Chinese with English summary], (3), 89-107.

Ting, G. (1997). Forms and characteristics of China's corruption in the 1990s: Change with continuity. Communist and PostCommunist Studies, 30, 277-288.

Wang, P. (2014). Extra-legal protection in China: How Guanxi distorts China's legal system and facilitates the rise of unlawful protectors. British Journal of Criminology, 54, 809-830.

Wang, P. (2016). Military corruption in China: The role of guanxi in the buying and selling of military positions. The China Quarterly, 228, 970-991.

Wedeman, A. (2004). The intensification of corruption in China. The China Quarterly, 180, 895-921.

Wedeman, A. (2012). Double paradox: Rapid growth and rising corruption in China. Ithica, NY: Cornell University Press.

Wei, C.F., \& Hwang, K.K. (1998). Positive duties and negative duties: A cross-cultural comparison of moral judgement between Taiwanese and American college students. Chinese Journal Psychology (in Traditional Chinese), 40, 137-153.

Weiss, R.S. (1995). Learning from strangers: The art and method of qualitative interview studies. New York, NY: Simon and Schuster.

Wu, M. (2016). An analysis of traditional cultural factors' influences on anti-corruption in China. Journal of Beijing College of Politics \& Law [in Chinese with English summary], (1), 106-109.

Xu, Y. (2011, July). Psychological kidnap: A new model of corruption process in China. Paper presented at the 9th Biennial Conference of Asian Association of Social Psychology, Yunnan.

Yang, Y. (1995). Analysis of interpersonal relationship and its classification-discussion with Mr. Hwang Kwang Kuo. Sociological Research [in Chinese], (5), 18-23.

Yang, Z., \& Wang, C.L. (2011). Guanxi as a governance mechanism in business markets: Its characteristics, relevant theories, and future research directions. Industrial Marketing Management, 40, 492-495.

Yu, O. (2008). Corruption in China's economic reform: A review of recent observations and explanations. Crime, Law and Social Change, 50, 161-176.

Zhai, X. (2005). Reproduction of renqing, mianzi and power [in Chinese]. Beijing, China: Peking University Press.

Zhan, J.V. (2012). Filling the gap of formal institutions: The effects of Guanxi network on corruption in reform-era China. Crime, Law and Social Change, 58, 93-109. 